\title{
COVID-19 and COPD
}

\section{CrossMark}

\author{
Janice M. Leung ${ }^{1,2}$, Masahiro Niikura (1) ${ }^{3}$, Cheng Wei Tony Yang (i) ${ }^{1}$ and \\ Don D. $\operatorname{Sin}^{1,2}$
}

Affiliations: ${ }^{1}$ Centre for Heart Lung Innovation, University of British Columbia, Vancouver, BC, Canada. ${ }^{2}$ Division of Respiratory Medicine, Dept of Medicine, University of British Columbia, Vancouver, BC, Canada. ${ }^{3}$ Faculty of Health Sciences, Simon Fraser University, Burnaby, BC, Canada.

Correspondence: Don D. Sin, St. Paul's Hospital, 1081 Burrard Street, Vancouver, BC. Canada V6Z 1 Y6. E-mail: don.sinahli.ubc.ca

@ERSpublications

COPD patients have increased risk of severe pneumonia and poor outcomes when they develop COVID-19. This may be related to poor underlying lung reserves or increased expression of ACE-2 receptor in small airways. https://bit.ly/37dSB81

Cite this article as: Leung JM, Niikura M, Yang CWT, et al. COVID-19 and COPD. Eur Respir J 2020; 56: 2002108 [https://doi.org/10.1183/13993003.02108-2020].

\section{Is COPD a risk factor for COVID-19?}

As of 11 July, 2020, severe acute respiratory syndrome coronavirus 2 (SARS-CoV-2), the virus responsible for the coronavirus disease 2019 (COVID-19) pandemic has infected over 12.7 million people around the world and caused more than 560,000 deaths [1]. Given the devastating impact that COVID-19 can have on the lung, it is natural to fear for patients with underlying COPD. Estimating their excess risk for contracting COVID-19 and, in particular, its more severe respiratory manifestations has been a challenging exercise in this pandemic for various reasons. First, the reporting on cases has concentrated on hospitalised and intensive care unit (ICU) patients, rather than on mild, outpatient cases. This is in part also due to the variability in testing strategies across the world, where some nations with stricter testing requirements and scarce testing resources have focused on testing only those requiring hospitalisation. We have also not yet quantified how many COPD patients might have chosen never to present to a hospital in this pandemic, only to subsequently appear in the statistics for excess mortality during this time $[2,3]$. Second, the underestimation of COPD in the general population is a problem that predates the COVID-19 era [4-6] and one that is likely to be exacerbated in overburdened hospitals where the precise ascertainment of comorbidities may be overlooked and spirometry cannot be performed. Moreover, how the diagnosis of COPD has been adjudicated in these studies has not been clearly delineated, possibly giving rise to variability in prevalence across the world.

Due to the earlier time course of infections there, our most thorough snapshot of COPD in COVID-19 is from China, where the background rate of COPD is $13.6 \%$ in adults aged $>40$ years [7]. The vast majority of these studies have centred on hospitalised patients, with only one to date including both hospitalised patients and outpatients (of which only $1.1 \%$ carried a diagnosis of COPD [8]) and one considering asymptomatic patients (of which only $1.6 \%$ had COPD [9]). For cohorts in China reporting on hospitalised patients, the prevalence of COPD has ranged from 0 to 10\% (table 1) [10-41]. As data from other nations have trickled in, the figures for COPD amongst hospitalised COVID-19 patients appear to be similar, with estimates in New York City ranging from 2.4 to $14 \%$ [42-45] and in Italy ranging from 5.6 to $9.2 \%$ [46-48]. Data from ICU-only cohorts, however, have been more variable. One cohort in Italy totalling 1591 ICU patients [49] and one in Seattle with 24 ICU patients noted COPD rates of 4\% in each [50]. Much higher prevalence has been reported in a Spanish ICU of 48 patients, of which 38\% had COPD [51], and in another Seattle ICU of 
TABLE 1 COPD and smoking prevalence in coronavirus disease 2019 patients

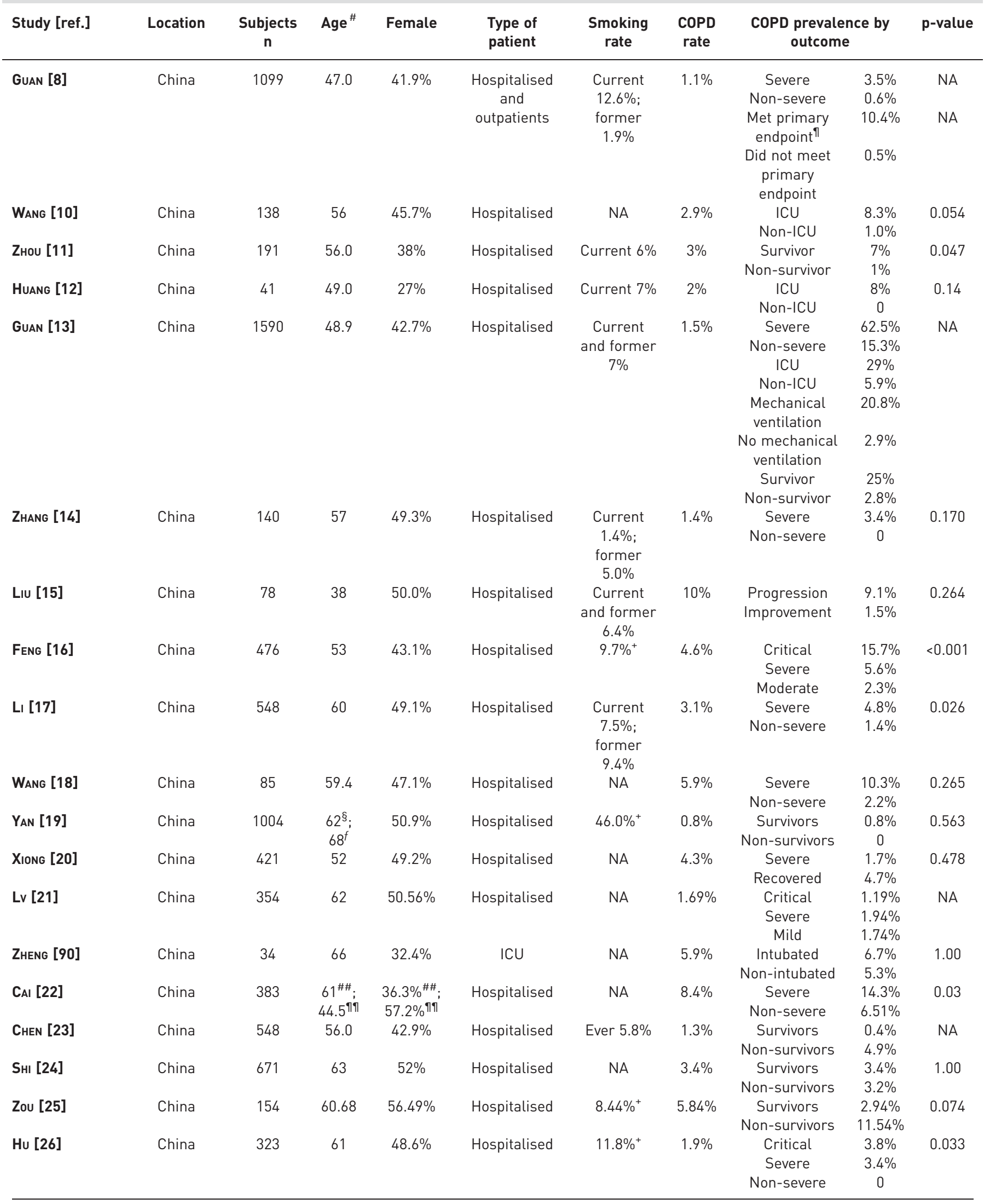


TABLE 1 Continued

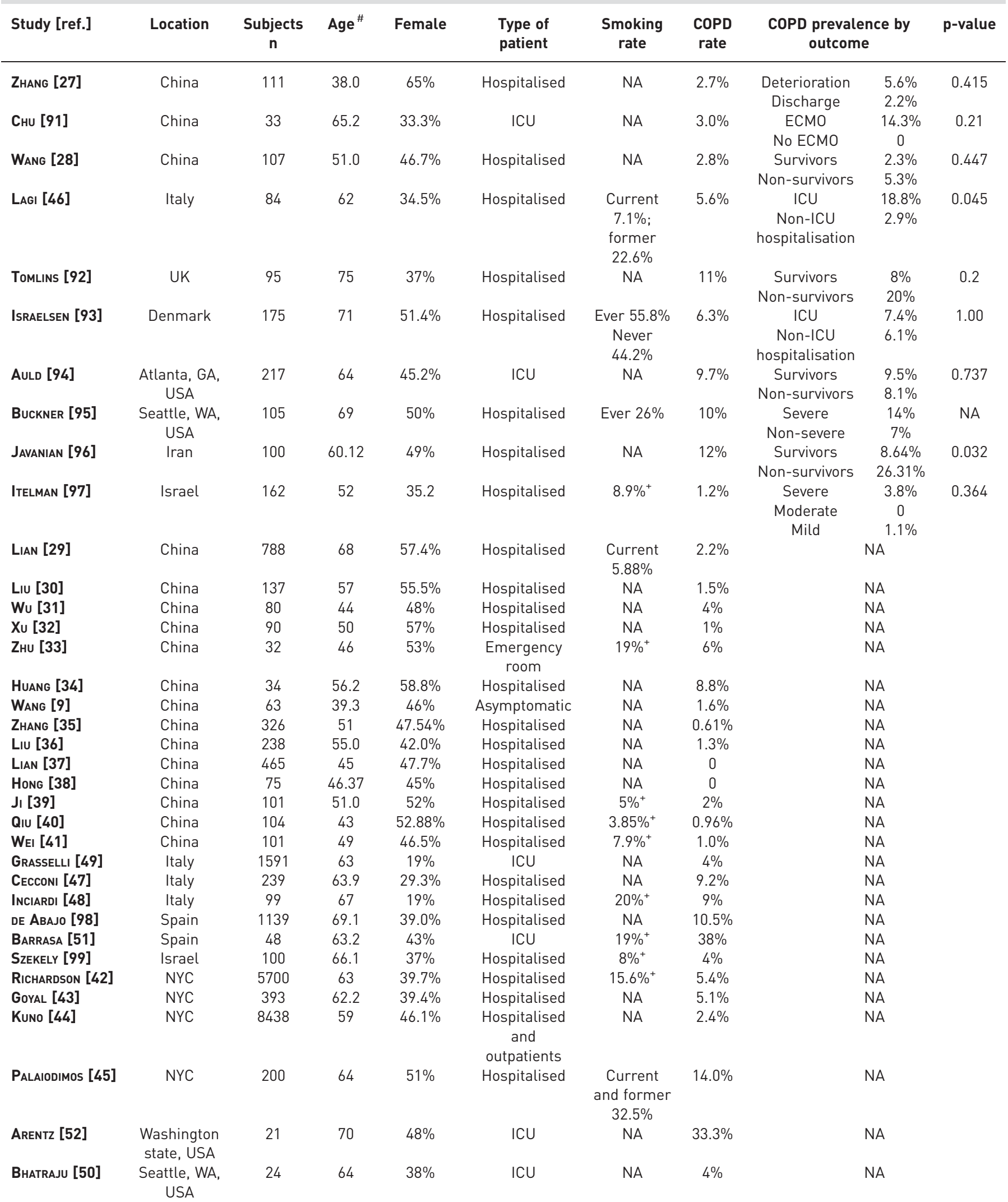




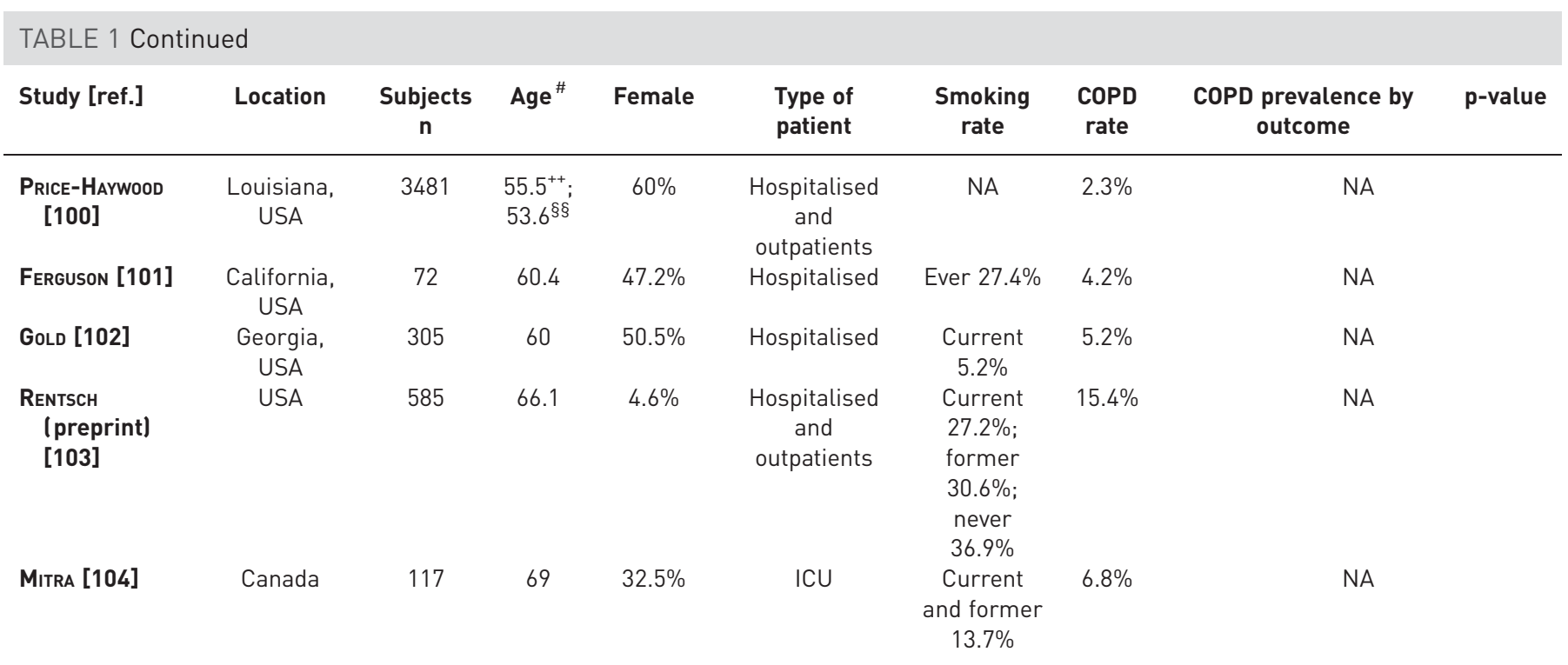

NYC: New York City, NY, USA. \# : median or mean ages, years; ๆ: ICU, mechanical ventilation or death; ${ }^{+}$: smoking status (i.e. current or former)

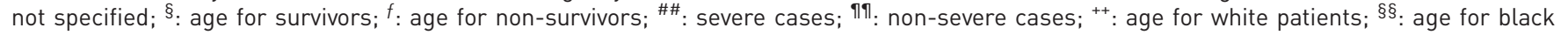
patients. NA: not available.

21 patients, where 33\% had COPD [52], although the small size of these studies must be kept in mind. To provide context, the prevalence of COPD in northern Italy, Spain, New York state, and Washington state is $11.7 \%$ [53], 10.2\% [54], 5.8\% [55], and 4.1\% [56], respectively. Other cohorts that have reported more broadly on chronic pulmonary diseases without necessarily specifying COPD still show considerable variability. These numbers have ranged from as low as $2.0 \%$ in a Shanghai cohort of 249 hospitalised patients, to up to $17.7 \%$ of 20133 hospitalised patients in the UK. Still, these numbers are less than those reported for other comorbidities, such as hypertension and diabetes.

Nonetheless, there is increasing evidence that COPD may be a risk factor for more severe COVID-19 disease [57]. An analysis of comorbidities in 1590 COVID-19 patients across China found that COPD carried an odds ratio of 2.681 (95\% CI 1.424-5.048; $\mathrm{p}=0.002$ ) for ICU admission, mechanical ventilation or death, even after adjustment for age and smoking [13]; $62.5 \%$ of severe cases had a history of COPD (compared with only $15.3 \%$ in non-severe cases) and $25 \%$ of those who died were COPD patients (compared with only $2.8 \%$ in those who survived). In a multicentre Chinese study, COPD patients made up $15.7 \%$ of the critically ill patients, but only $2.3 \%$ of moderately ill patients $(\mathrm{p}<0.001)$ [16]. Other studies have found similar, if statistically weaker, differences in COPD rates between ICU admissions and non-ICU admissions ( $8.3 \%$ versus $1.0 \% ; \mathrm{p}=0.054)$ [10], severe and non-severe cases ( $4.8 \%$ versus $1.4 \%$; $\mathrm{p}=0.026$ ) [17], and between non-survivors and survivors (7\% versus $1 \% ; \mathrm{p}=0.047)$ [11].

\section{The COPD airway in COVID-19}

Why COPD patients appear to suffer worse outcomes upon contracting COVID-19 (even if their risk of contracting to begin with may not be high) is worth some speculation. First, recent evidence that COPD patients and smokers may display the machinery required for SARS-CoV-2 cellular entry differently has come to light. Similar to SARS-CoV (which was responsible for the 2002-2003 SARS pandemic) [58], SARS-CoV-2 bears an envelope spike protein that is primed by the cellular serine protease TMPRSS2 to facilitate fusion of the virus with the cell's angiotensin-converting enzyme 2 (ACE-2) receptor and subsequent cell entry (figure 1) [59-62]. Our group has recently demonstrated that in three separate cohorts with available gene expression profiles from bronchial epithelial cells, ACE-2 expression was significantly elevated in COPD patients compared to control subjects [63]. Current smoking was also associated with higher ACE-2 expression compared with former and never smokers, an observation which has subsequently been validated by other groups in separate cohorts of lung tissue and airway epithelial samples [64-66] and supported by additional evidence linking ACE-2 expression with nicotine exposure $[67,68]$. It is important to note, though, that ACE-2 expression alone has not been shown yet to confer increased susceptibility or increased severity of disease. Moreover, the relatively low expression of ACE-2 in the bronchial epithelium in comparison to the nasal epithelium [69] has unclear implications for disease susceptibility in patients with predominantly small airways pathology. 

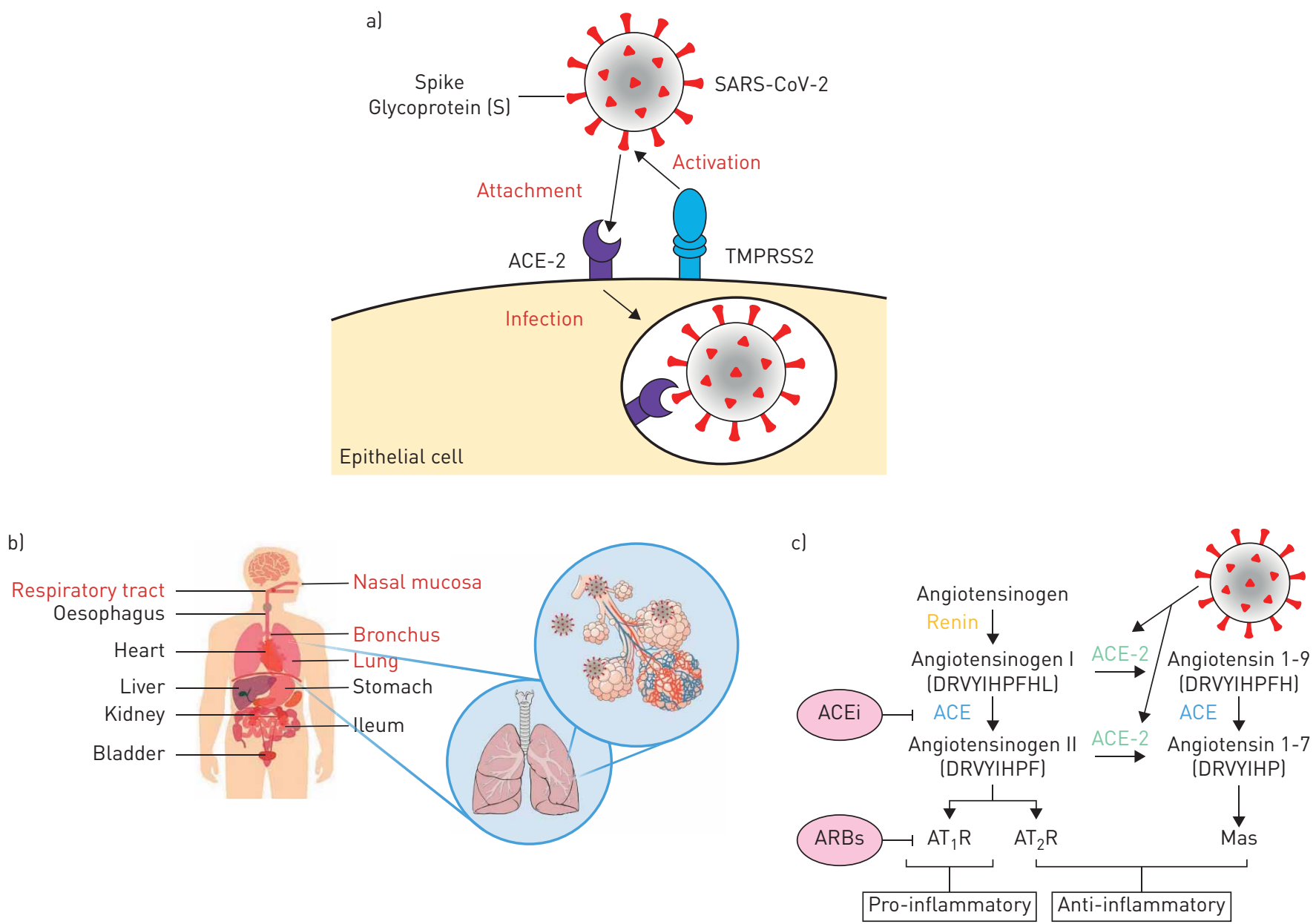

FIGURE 1 Schematic representation of a) severe acute respiratory syndrome coronavirus 2 (SARS-CoV-2) binding to the angiotensin-converting enzyme 2 (ACE-2) receptor following activation of the spike protein (s) by transmembrane serine protease 2 (TMPRSS2), which leads to endocytosis and infection. b) Human organs that have been reported by Zou et al. [105] to show ACE2 expression, with the respiratory system highlighted in red. c) The renin-angiotensin system (RAS) and the proposed SARS-CoV-2 action. The generation of angiotensin II from angiotensin I by angiotensin-converting enzyme (ACE) induces vasoconstriction of blood vessels and pro-inflammatory effects through the binding of angiotensin II receptor type $1\left(A T_{1} R\right)$, while the receptor type $2\left(A T_{2} R\right)$ may negatively regulate this pathway. ACE inhibitors (ACEi) and angiotensin II receptor blockers (ARBs) are very successful anti-hypertensives by promoting vasodilation of blood vessels. ACE-2 inhibits the activity of angiotensin II by converting angiotensin I to angiotensin 1-9 and angiotensin II to angiotensin 1-7, which binds to the MAS1 proto-oncogene (Mas) receptor with anti-inflammatory effects. Upon SARS-CoV-2 binding to ACE-2, there is a shift in the ACE/ACE-2 balance towards a predominance of ACE, resulting in increased pro-inflammatory effects and tissue damage.

\section{The management of COPD patients during the COVID-19 pandemic}

Two challenges of clinical care in COPD have emerged during this pandemic: 1) whether the usual algorithms of pharmaceutical management in COPD still apply and 2) how to weather the dramatic curtailments in non-pharmaceutical interventions this pandemic has wrought. Although our understanding of COVID-19 has substantially increased in a short period of time, these problems have largely been the domain of expert opinion rather than being guided by rigorous scientific evidence.

Questions remain about the effects of common respiratory medications used by our COPD patients such as inhaled (ICS) and systemic corticosteroids, short- and long-acting $\beta_{2}$-agonists, and short- and long-acting muscarinic antagonists in either mitigating or exacerbating COVID-19 infections. The epidemiological data emerging from China and other early epicentres have not yet provided the necessary granularity required to determine whether these medications are harmful or beneficial in COVID-19 patients with COPD. PETERs et al. [70], however, have recently shown that ACE-2 expression in airway epithelial cells obtained from asthmatic patients was decreased in those taking ICS compared to those who were not on ICS, raising the possibility that ICS exposure could decrease viral entry. Whether the same relationship holds true in the COPD airway, in which the predisposition to pneumonia following ICS use is well-documented, has not yet been established. For now, in the absence of data demonstrating definitive 
harm or benefit, ICS and other long-acting inhalers should not be routinely withdrawn nor should their use be escalated as a preventative measure for COPD patients during this pandemic [71].

Of greater concern is the use of systemic corticosteroids, the backbone of COPD exacerbation treatment. On balance, the historical evidence for systemic corticosteroids in viral pandemics has not been entirely favourable. Lessons from the SARS and Middle East respiratory syndrome (MERS) pandemics suggest potential harm, in fact. In SARS, while the majority of studies were inconclusive, four studies showed harm, including delayed viral clearance and increased rates of psychosis [72]. In MERS, corticosteroid use was associated with increased mortality [73] and delayed viral clearance [74]. So far, the most promising preliminary data on corticosteroids and COVID-19 are from a randomised controlled trial of dexamethasone (RECOVERY) performed in the UK, which demonstrated a one-third reduction in mortality [75]. Published data, however, are derived from small retrospective studies and appear mixed, with two studies showing no benefit $[76,77]$ and two studies showing improvements in rates of death and escalation of care [78, 79]. Because of the results of the RECOVERY trial, however, it is likely that dexamethasone will become standard of care treatment for COVID-19 patients including those with COPD.

The impact of the pandemic has been keenly felt by COPD patients in myriad aspects of their lives. Face-to-face clinic visits with their physicians have been curtailed, as have pulmonary rehabilitation sessions and COPD home visit programmes. Patients who may have normally presented to the hospital during an exacerbation might choose to stay home for fear of exposure, resulting in delayed care, as has occurred in other conditions like myocardial infarction $[80,81]$. The long-term effects of this pause in routine care have yet to be measured. For now, healthcare systems have had to adapt to these conditions by augmenting telehealth and virtual visits. Fortunately, multiple randomised controlled trials assessing telehealth for COPD patients have demonstrated its feasibility and at least non-inferiority to usual care when it comes to exacerbations, hospitalisations and quality of life [82-86]. Moreover, online pulmonary rehabilitation programmes appear to be as effective as in-person sessions [87-89]. In the event that social distancing measures remain in place for many more months, we advocate for the establishment of these virtual programmes to ensure our patient population can continue to receive optimal care.

\section{Directions for COVID-19 and COPD research}

Specifically, we will have to address the following questions on COVID-19 as they pertain to COPD:

- Does the burden of disease, clinical manifestations, and outcomes of COVID-19 in COPD patients differ from the general population and if so, how?

- Given the multiple phenotypes associated with the term "COPD" (i.e. frequent exacerbators, emphysema-predominant, eosinophilic-predominant, asthma overlap), does COVID-19 infection in each of these phenotypes present and behave differently?

- Are routine medications used in COPD such as inhaled and systemic corticosteroids, $\beta_{2}$-agonists, muscarinic antagonists and chronic azithromycin protective or harmful in the setting of COVID-19 infection?

- What will the impact of post-COVID-19 infection disability be in COPD patients and what resources will be required to adequately support the transition of COPD patients from the hospital to home after COVID-19?

- How can we manipulate the unique airway pathology of COPD patients and the ACE-2 system to identify novel therapeutics?

- What is the role of inhaled substances (e.g. tobacco, cannabis and e-cigarettes) and air pollution in increasing the susceptibility of COPD patients to COVID-19?

- What can we learn from the experience of virtual care to COPD patients during this pandemic that can be applied in future scenarios to reach isolated patient populations and resource limited settings?

These research questions can best be answered by developing standards for transparent data reporting across the globe and harnessing the power of international networks that can quickly collate the data of COVID-19 COPD patients. Similarly, the efforts of translational research scientists at the laboratory bench who are working to characterise the pathophysiology of COVID-19 infections in the airway are critical to developing new therapies for a world in which there are currently very few.

Acknowledgement: The authors would like to thank Irving Ding and Chun Hong Tao for their financial support of the SPF COVID-19 Response Fund. D.D. Sin holds a Tier 1 Canada Research Chair in COPD and the de Lazzari Family Chair at the Centre for Heart Lung Innovation. J.M. Leung is supported by the Michael Smith Foundation for Health Research (MSFHR)/Providence Health Care Health Professional Investigator (HPI) Award and by the Canadian Institutes of Health Research (CIHR)/AstraZeneca Early Career Investigator Award.

Conflict of interest: J.M. Leung has nothing to disclose. M. Niikura has nothing to disclose. C.W.T. Yang has nothing to disclose. D.D. Sin reports grants from Merck, personal fees for advisory board work from Sanofi-Aventis and 
Regeneron, grants and personal fees for lectures from Boehringer Ingelheim and AstraZeneca, personal fees for lectures and advisory board work from Novartis, outside the submitted work.

Support statement: This work was supported by the St. Paul's Foundation (SPF) COVID-19 Response Fund.

\section{References}

1 Coronavirus Worldometer. www.worldometers.info/coronavirus/ Date last accessed: 11 July 2020.

2 Centers for Disesase Control and Prevention. Excess Deaths Associated with COVID-19. 2020. www.cdc.gov/ nchs/nvss/vsrr/covid19/excess_deaths.htm Date last accessed: 3 May 2020.

3 Michelozzi P, de'Donato F, Scortichini M, et al. Mortality impacts of the coronavirus disease (COVID-19) outbreak by sex and age: rapid mortality surveillance system, Italy, 1 February to 18 April 2020. Euro Surveill 2020; 25: 2000620.

4 Gershon AS, Thiruchelvam D, Chapman KR, et al. Health services burden of undiagnosed and overdiagnosed COPD. Chest 2018; 153: 1336-1346.

5 Labonte LE, Tan WC, Li PZ, et al. Undiagnosed chronic obstructive pulmonary disease contributes to the burden of health care use. Data from the CanCOLD Study. Am J Respir Crit Care Med 2016; 194: 285-298.

6 Martinez CH, Mannino DM, Jaimes FA, et al. Undiagnosed obstructive lung disease in the United States. Associated factors and long-term mortality. Ann Am Thorac Soc 2015; 12: 1788-1795.

7 Fang L, Gao P, Bao H, et al. Chronic obstructive pulmonary disease in China: a nationwide prevalence study. Lancet Respir Med 2018; 6: 421-430.

8 Guan WJ, Ni ZY, Hu Y, et al. Clinical characteristics of coronavirus disease 2019 in China. N Engl J Med 2020; 382: $1708-1720$.

9 Wang Y, Tong J, Qin Y, et al. Characterization of an asymptomatic cohort of SARS-COV-2 infected individuals outside of Wuhan, China. Clin Infect Dis 2020; in press [https://doi.org/10.1093/cid/ciaa629].

10 Wang $\mathrm{D}, \mathrm{Hu} \mathrm{B}, \mathrm{Hu} \mathrm{C}$, et al. Clinical characteristics of 138 hospitalized patients with 2019 novel coronavirus-infected pneumonia in Wuhan, China. JAMA 2020; 323: 1061-1069.

11 Zhou F, Yu T, Du R, et al. Clinical course and risk factors for mortality of adult inpatients with COVID-19 in Wuhan, China: a retrospective cohort study. Lancet 2020; 395: 1054-1062.

12 Huang C, Wang Y, Li X, et al. Clinical features of patients infected with 2019 novel coronavirus in Wuhan, China. Lancet 2020; 395: 497-506.

13 Guan WJ, Liang WH, Zhao Y, et al. Comorbidity and its impact on 1590 patients with Covid-19 in China: a nationwide analysis. Eur Respir J 2020; 55: 2000547.

14 Zhang JJ, Dong X, Cao YY, et al. Clinical characteristics of 140 patients infected with SARS-CoV-2 in Wuhan, China. Allergy 2020; 75: 1730-1741.

15 Liu W, Tao ZW, Lei W, et al. Analysis of factors associated with disease outcomes in hospitalized patients with 2019 novel coronavirus disease. Chin Med J (Engl) 2020; 133: 1032-1038.

16 Feng Y, Ling Y, Bai T, et al. COVID-19 with different severity: a multi-center study of clinical features. Am J Respir Crit Care Med 2020; 201: 1380-1388.

17 Li X, Xu S, Yu M, et al. Risk factors for severity and mortality in adult COVID-19 inpatients in Wuhan. J Allergy Clin Immunol 2020; 146: 110-118.

18 Wang CZ, Hu SL, Wang L, et al. Early risk factors of the exacerbation of coronavirus disease 2019 pneumonia. J Med Virol 2020; in press [https://doi.org/10.1002/jmv.26071].

19 Yan X, Li F, Wang X, et al. Neutrophil to lymphocyte ratio as prognostic and predictive factor in patients with coronavirus disease 2019: a retrospective cross-sectional study. J Med Virol 2020; in press [https://doi.org/10. 1002/jmv.26061].

20 Xiong Z, Xin C, Yan MX, et al. Clinical characteristics and outcomes of 421 patients with COVID-19 treated in a mobile cabin hospital. Chest 2020; in press [https://doi.org/10.1016/j.chest.2020.05.515].

21 Lv Z, Cheng S, Le J, et al. Clinical characteristics and co-infections of 354 hospitalized patients with COVID-19 in Wuhan, China: a retrospective cohort study. Microbes Infect 2020; 22: 195-199.

22 Cai Q, Chen F, Wang T, et al. Obesity and COVID-19 severity in a designated hospital in Shenzhen, China. Diabetes Care 2020; 43: 1392-1398.

23 Chen R, Sang L, Jiang M, et al. Longitudinal hematologic and immunologic variations associated with the progression of COVID-19 patients in China. J Allergy Clin Immunol 2020; 146: 89-100.

24 Shi S, Qin M, Cai Y, et al. Characteristics and clinical significance of myocardial injury in patients with severe coronavirus disease 2019. Eur Heart J 2020; 41: 2070-2079.

25 Zou X, Li S, Fang M, et al. Acute Physiology and Chronic Health Evaluation II Score as a predictor of hospital mortality in patients of coronavirus disease 2019. Crit Care Med 2020; 48: e657-e665.

$26 \mathrm{Hu} \mathrm{L}$, Chen S, Fu Y, et al. Risk factors associated with clinical outcomes in 323 COVID-19 hospitalized patients in Wuhan, China. Clin Infect Dis 2020; in press [https://doi.org/10.1093/cid/ciaa539].

27 Zhang J, Yu M, Tong S, et al. Predictive factors for disease progression in hospitalized patients with coronavirus disease 2019 in Wuhan, China. J Clin Virol 2020; 127: 104392.

28 Wang D, Yin Y, Hu C, et al. Clinical course and outcome of 107 patients infected with the novel coronavirus, SARS-CoV-2, discharged from two hospitals in Wuhan, China. Crit Care 2020; 24: 188.

29 Lian J, Jin X, Hao S, et al. Analysis of epidemiological and clinical features in older patients with corona virus disease 2019 (COVID-19) out of Wuhan. Clin Infect Dis 2020; 71: 740-747.

30 Liu K, Fang YY, Deng Y, et al. Clinical characteristics of novel coronavirus cases in tertiary hospitals in Hubei Province. Chin Med J 2020; 133: 1025-1031.

$31 \mathrm{Wu}$ J, Wu X, Zeng W, et al. Chest CT findings in patients with coronavirus disease 2019 and its relationship with clinical features. Invest Radiol 2020; 55: 257-261.

$32 \mathrm{Xu} \mathrm{X}, \mathrm{Yu} \mathrm{C}, \mathrm{Qu} \mathrm{J}$, et al. Imaging and clinical features of patients with 2019 novel coronavirus SARS-CoV-2. Eur J Nucl Med Mol Imaging 2020; 47: 1275-1280.

33 Zhu W, Xie K, Lu H, et al. Initial clinical features of suspected coronavirus disease 2019 in two emergency departments outside of Hubei, China. J Med Virol 2020; in press [https://doi.org/10.1002/jmv.25763]. 

infection in Wuhan, China: a retrospective single center analysis. Travel Med Infect Dis 2020; in press [https://doi.org/10.1016/j.tmaid.2020.101606].

35 Zhang X, Tan Y, Ling Y, et al. Viral and host factors related to the clinical outcome of COVID-19. Nature 2020; 583: $437-440$

36 Liu L, Liu W, Zheng Y, et al. A preliminary study on serological assay for severe acute respiratory syndrome coronavirus 2 (SARS-CoV-2) in 238 admitted hospital patients. Microbes Infect 2020; 22: 206-211.

37 Lian J, Jin X, Hao S, et al. Epidemiological, clinical, and virological characteristics of 465 hospitalized cases of coronavirus disease 2019 (COVID-19) from Zhejiang province in China. Influenza Other Respir Viruses 2020; in press [https://doi.org/10.1111/irv.12758].

38 Hong Y, Wu X, Qu J, et al. Clinical characteristics of coronavirus disease 2019 and development of a prediction model for prolonged hospital length of stay. Ann Transl Med 2020; 8: 443.

39 Ji M, Yuan L, Shen W, et al. Characteristics of disease progress in patients with coronavirus disease 2019 in Wuhan, China. Epidemiol Infect 2020; 148: e94.

40 Qiu C, Deng Z, Xiao Q, et al. Transmission and clinical characteristics of coronavirus disease 2019 in 104 outside-Wuhan patients, China. J Med Virol 2020; in press [https://doi.org/10.1002/jmv.25975].

41 Wei JF, Huang FY, Xiong TY, et al. Acute myocardial injury is common in patients with COVID-19 and impairs their prognosis. Heart 2020; 106: 1154-1159.

42 Richardson S, Hirsch JS, Narasimhan M, et al. Presenting characteristics, comorbidities, and outcomes among 5700 patients hospitalized with COVID-19 in the New York City Area. JAMA 2020; 323: 2052-2059.

43 Goyal P, Choi JJ, Pinheiro LC, et al. Clinical characteristics of Covid-19 in New York City. N Engl J Med 2020; 382: 2372-2374.

44 Kuno T, Takahashi M, Obata R, et al. Cardiovascular comorbidities, cardiac injury and prognosis of COVID-19 in New York City. Am Heart J 2020; 226: 24-25.

45 Palaiodimos L, Kokkinidis DG, Li W, et al. Severe obesity, increasing age and male sex are independently associated with worse in-hospital outcomes, and higher in-hospital mortality, in a cohort of patients with COVID-19 in the Bronx, New York. Metab Clin Exp 2020; 108: 154262.

46 Lagi F, Piccica M, Graziani L, et al. Early experience of an infectious and tropical diseases unit during the coronavirus disease (COVID-19) pandemic, Florence, Italy, February to March 2020. Euro Surveill 2020; 25: 2000556.

47 Cecconi M, Piovani D, Brunetta E, et al. Early predictors of clinical deterioration in a cohort of 239 patients hospitalized for Covid-19 infection in Lombardy, Italy. J Clin Med 2020; 9: 1548.

48 Inciardi RM, Adamo M, Lupi L, et al. Characteristics and outcomes of patients hospitalized for COVID-19 and cardiac disease in Northern Italy. Eur Heart J 2020; 41: 1821-1829.

49 Grasselli G, Zangrillo A, Zanella A, et al. Baseline characteristics and outcomes of 1591 patients infected with SARS-CoV-2 admitted to ICUs of the Lombardy Region, Italy. JAMA 2020; 323: 1574-1581.

50 Bhatraju PK, Ghassemieh BJ, Nichols M, et al. Covid-19 in critically ill patients in the Seattle region - case series. N Engl J Med 2020; 382: 2012-2022.

51 Barrasa H, Rello J, Tejada S, et al. SARS-Cov-2 in Spanish intensive care: early experience with 15-day survival in Vitoria. Anaesth Crit Care Pain Med 2020; in press [https://doi.org/10.1016/j.accpm.2020.04.001].

52 Arentz M, Yim E, Klaff L, et al. Characteristics and outcomes of 21 critically ill patients with COVID-19 in Washington state. JAMA 2020; 323: 1612-1614.

53 Guerriero M, Caminati M, Viegi G, et al. COPD prevalence in a north-eastern Italian general population. Respir Med 2015; 109: 1040-1047.

54 Miravitlles M, Soriano JB, García-Río F, et al. Prevalence of COPD in Spain: impact of undiagnosed COPD on quality of life and daily life activities. Thorax 2009; 64: 863-868.

55 New York State Department of Health. Chronic Obstructive Pulmonary Disease, New York State Adults, 2015. 2015 www.health.ny.gov/statistics/brfss/reports/docs/1715_brfss_pulmonary.pdf Date last accessed: 30 May 2020.

56 Centers for Disease Control and Prevention. COPD among adults in Washington. 2018 www.cdc.gov/copd/maps/ docs/pdf/WA_COPDFactSheet.pdf Date last accessed: 30 May 2020.

57 Alqahtani JS, Oyelade T, Aldhahir AM, et al. Prevalence, severity and mortality associated with COPD and smoking in patients with COVID-19: a rapid systematic review and meta-analysis. PLoS One 2020; 15 : e0233147.

$58 \mathrm{Li}$ W, Moore MJ, Vasilieva N, et al. Angiotensin-converting enzyme 2 is a functional receptor for the SARS coronavirus. Nature 2003; 426: 450-454.

59 Hoffmann M, Kleine-Weber H, Schroeder S, et al. SARS-CoV-2 cell entry depends on ACE2 and TMPRSS2 and is blocked by a clinically proven protease inhibitor. Cell 2020; 181: 271-280.

60 Letko M, Marzi A, Munster V. Functional assessment of cell entry and receptor usage for SARS-CoV-2 and other lineage B betacoronaviruses. Nat Microbiol 2020; 5: 562-569.

61 Walls AC, Park YJ, Tortorici MA, et al. Structure, Function, and Antigenicity of the SARS-CoV-2 Spike Glycoprotein. Cell 2020; 181: 281-292.

62 Zhou P, Yang XL, Wang XG, et al. A pneumonia outbreak associated with a new coronavirus of probable bat origin. Nature 2020; 579: 270-273.

63 Leung JM, Yang CX, Tam A, et al. ACE-2 Expression in the small airway epithelia of smokers and COPD patients: implications for COVID-19. Eur Respir J 2020; 55: 2000688.

64 Cai G, Bosse Y, Xiao F, et al. Tobacco smoking increases the lung gene expression of ACE2, the receptor of SARS-CoV-2. Am J Respir Crit Care Med 2020; 201: 1557-1559.

65 Li G, He X, Zhang L, et al. Assessing ACE2 expression patterns in lung tissues in the pathogenesis of COVID-19. J Autoimmun 2020; 112: 102463.

66 Zhang H, Rostami MR, Leopold PL, et al. Expression of the SARS-CoV-2 ACE2 receptor in the human airway epithelium. Am J Respir Crit Care Med 2020; 202: 219-229.

67 Leung JM, Yang CX, Sin DD. COVID-19 and nicotine as a mediator of ACE-2. Eur Respir J 2020; 55: 2001261.

68 Russo P, Bonassi S, Giacconi R, et al. COVID-19 and smoking: is nicotine the hidden link? Eur Respir J 2020; 55: 2001116.

69 Sungnak W, Huang N, Becavin C, et al. SARS-CoV-2 entry factors are highly expressed in nasal epithelial cells together with innate immune genes. Nat Med 2020; 26: 681-687. 
Peters MC, Sajuthi S, Deford P, et al. COVID-19 related genes in sputum cells in asthma: relationship to demographic features and corticosteroids. Am J Respir Crit Care Med 2020; 202: 83-90.

Halpin DMG, Singh D, Hadfield RM. Inhaled corticosteroids and COVID-19: a systematic review and clinical perspective. Eur Respir J 2020; 55: 2001009.

Stockman LJ, Bellamy R, Garner P. SARS: systematic review of treatment effects. PLoS Med 2006; 3: e343.

Alfaraj SH, Al-Tawfiq JA, Assiri AY, et al. Clinical predictors of mortality of Middle East respiratory syndrome coronavirus (MERS-CoV) infection: a cohort study. Travel Med Infect Dis 2019; 29: 48-50. respiratory syndrome. Am J Respir Crit Care Med 2018; 197: 757-767.

Horby P, Lim WS, Emberson J, et al. Effect of dexamethasone in hospitalized patients with COVID-19: preliminary report. medRxiv 2020; preprint [https://doi.org/10.1101/2020.06.22.20137273].

Zha L, Li S, Pan L, et al. Corticosteroid treatment of patients with coronavirus disease 2019 (COVID-19). Med J Aust 2020; 212: 416-420.

$\mathrm{Lu}$ X, Chen T, Wang Y, et al. Adjuvant corticosteroid therapy for critically ill patients with COVID-19. Crit Care 2020; 24: 241.

Wu C, Chen X, Cai Y, et al. Risk factors associated with acute respiratory distress syndrome and death in patients with coronavirus disease 2019 pneumonia in Wuhan, China. JAMA Intern Med 2020; 180: 934-943.

Fadel R, Morrison AR, Vahia A, et al. Early short course corticosteroids in hospitalized patients with COVID-19. Clin Infect Dis 2020; in press [https://doi.org/10.1093/cid/ciaa601].

Tam CF, Cheung KS, Lam S, et al. Impact of coronavirus disease 2019 (COVID-19) outbreak on ST-segmentelevation myocardial infarction care in Hong Kong, China. Circ Cardiovasc Qual Outcomes 2020; 13: e006631.

Tam CF, Cheung KS, Lam S, et al. Impact of coronavirus disease 2019 (COVID-19) outbreak on outcome of myocardial infarction in Hong Kong, China. Catheter Cardiovasc Interv 2020; in press [https://doi.org/10.1002/ ccd.28943].

Pinnock H, Hanley J, McCloughan L, et al. Effectiveness of telemonitoring integrated into existing clinical services on hospital admission for exacerbation of chronic obstructive pulmonary disease: researcher blind, multicentre, randomised controlled trial. BMJ 2013; 347: f6070.

McDowell JE, McClean S, FitzGibbon F, et al. A randomised clinical trial of the effectiveness of home-based health care with telemonitoring in patients with COPD. J Telemed Telecare 2015; 21: 80-87.

Au DH, Macaulay DS, Jarvis JL, et al. Impact of a telehealth and care management program for patients with chronic obstructive pulmonary disease. Ann Am Thorac Soc 2015; 12: 323-331.

Hardinge M, Rutter H, Velardo C, et al. Using a mobile health application to support self-management in chronic obstructive pulmonary disease: a six-month cohort study. BMC Med Inform Decis Mak 2015; 15: 46.

Ho TW, Huang CT, Chiu HC, et al. Effectiveness of telemonitoring in patients with chronic obstructive pulmonary disease in Taiwan-a randomized controlled trial. Sci Rep 2016; 6: 23797.

Bourne S, DeVos R, North M, et al. Online versus face-to-face pulmonary rehabilitation for patients with chronic obstructive pulmonary disease: randomised controlled trial. BMJ Open 2017; 7: e014580.

Vasilopoulou M, Papaioannou AI, Kaltsakas G, et al. Home-based maintenance tele-rehabilitation reduces the risk for acute exacerbations of COPD, hospitalisations and emergency department visits. Eur Respir J 2017; 49: 1602129. Paneroni M, Colombo F, Papalia A, et al. Is telerehabilitation a safe and viable option for patients with COPD? A feasibility study. COPD 2015; 12: 217-225.

Zheng Y, Sun LJ, Xu M, et al. Clinical characteristics of 34 COVID-19 patients admitted to intensive care unit in Hangzhou, China. J Zhejiang Univ Sci B 2020; 21: 378-387.

Chu Y, Li T, Fang Q, et al. Clinical features of critically ill patients with confirmed COVID-19. J Infect 2020; 81: $147-178$.

Tomlins J, Hamilton F, Gunning S, et al. Clinical features of 95 sequential hospitalised patients with novel coronavirus 2019 disease (COVID-19), the first UK cohort. J Infect 2020; 81: e59-e61. Hvidovre Hospital, March-April 2020. Dan Med J 2020; 67: A05200313.

Auld SC, Caridi-Scheible M, Blum JM, et al. ICU and ventilator mortality among critically ill adults with coronavirus disease 2019. Crit Care Med 2020; in press [https://doi.org/10.1097/CCM.0000000000004457].

Buckner FS, McCulloch DJ, Atluri V, et al. Clinical features and outcomes of 105 hospitalized patients with COVID-19 in Seattle, Washington. Clin Infect Dis 2020; in press [https://doi.org/10.1093/cid/ciaa632].

Javanian M, Bayani M, Shokri M, et al. Clinical and laboratory findings from patients with COVID-19 pneumonia in Babol North of Iran: a retrospective cohort study. Rom J Intern Med 2020; in press [https://doi. org/10.2478/rjim-2020-0013]

Itelman E, Wasserstrum Y, Segev A, et al. Clinical characterization of 162 COVID-19 patients in Israel: preliminary report from a large tertiary center. Isr Med Assoc J 2020; 22: 271-274. of COVID-19 requiring admission to hospital: a case-population study. Lancet 2020; 395: 1705-1714.

Szekely Y, Lichter Y, Taieb P, et al. The spectrum of cardiac manifestations in coronavirus disease 2019 (COVID-19) - a systematic echocardiographic study. Circulation 2020; 142: 342-353.

Price-Haywood EG, Burton J, Fort D, et al. Hospitalization and mortality among black patients and white patients with Covid-19. N Engl J Med 2020; 382: 2534-2543.

Ferguson J, Rosser JI, Quintero O, et al. Characteristics and outcomes of coronavirus disease patients under nonsurge conditions, Northern California, USA, March-April 2020. Emerging Infect Dis 2020; 26: 1679-1685.

Gold JAW, Wong KK, Szablewski CM, et al. Characteristics and clinical outcomes of adult patients hospitalized with COVID-19 - Georgia, March 2020. MMWR Morb Mortal Wkly Rep 2020; 69: 545-550.

Rentsch CT, Kidwai-Khan F, Tate JP, et al. Covid-19 Testing, Hospital Admission, and Intensive Care Among 2,026,227 United States Veterans Aged 54-75 Years. medRxiv 2020; preprint [https://doi.org/10.1101/2020.04.09.20059964].

Mitra AR, Fergusson NA, Lloyd-Smith E, et al. Baseline characteristics and outcomes of patients with COVID-19 admitted to intensive care units in Vancouver, Canada: a case series. CMAJ 2020; 192: E694-E701.

Zou X, Chen K, Zou J, et al. Single-cell RNA-seq data analysis on the receptor ACE2 expression reveals the potential risk of different human organs vulnerable to 2019-nCoV infection. Front Med 2020; 14: 185-192. 